\title{
Efficient and low-energy mechanochemical extraction of lead from dumped crystal glass waste
}

\author{
Richard Nasilele Mutafela ${ }^{1}$ (D) Fei Ye ${ }^{2} \cdot$ Yahya Jani $^{1} \cdot$ Joydeep Dutta ${ }^{2} \cdot$ William Hogland $^{1}$
}

Received: 6 April 2020 / Accepted: 8 September 2020 / Published online: 30 September 2020

(c) The Author(s) 2020

\begin{abstract}
Glass waste dumps from crystal glass production is an health issue due to the occurrence of antimony, arsenic, cadmium and lead in crystal glass. Recovery of those elements could both decrease pollution and recycle metals in the circular economy. Pyrometallurgy is a potential recovery method, yet limited by high energy consumption. Here we tested a lower-energy alternative in which glass is mechanically activated in a ball mill and leached with nitric acid. Results show that mechanical activation destabilised the glass structure and resulted in $78 \%$ lead extraction during leaching at $95{ }^{\circ} \mathrm{C}$. Temperature had the most significant effect on extraction, whereas acid concentration, from 0.5 to $3 \mathrm{M}$, and leaching time, from 0.5 to $12 \mathrm{~h}$, had insignificant effects. In each experiment, $75 \%$ of the final extracted amount was achieved within $30 \mathrm{~min}$. The study demonstrates potential for lead extraction from glass waste at lower acid concentration, shorter leaching time and lower temperature, of $95^{\circ} \mathrm{C}$, than traditional pyrometallurgical extraction, typically operating at $1100{ }^{\circ} \mathrm{C}$.
\end{abstract}

Keywords Hazardous waste $\cdot$ Crystal glass $\cdot$ Mechanical activation $\cdot$ Acid leaching $\cdot$ Lead extraction $\cdot$ Circular economy

\section{Introduction}

Glassworks have been sources of anthropogenic pollutants around the world (Brião et al. 2020; Mutafela et al. 2020a; Rossini et al. 2010). Elements used in crystal glass, such as arsenic (As), cadmium $(\mathrm{Cd})$, antimony $(\mathrm{Sb})$ and lead $(\mathrm{Pb})$ end up in the environment through emissions, effluents and other factory wastes (Mutafela et al. 2020b). They can contaminate soil, surface and ground water, and pose human health hazards (Keng et al. 2014; Malik et al. 2019). In Sweden, contaminated glass dumps are excavated and materials landfilled as a remediation measure. Unlike transferring the contamination problem (Pasalari et al. 2019), remediation

Electronic supplementary material The online version of this article (https://doi.org/10.1007/s10311-020-01096-5) contains supplementary material, which is available to authorized users.

Richard Nasilele Mutafela

richardnasilele.mutafela@lnu.se

1 Department of Biology and Environmental Science, Faculty of Health and Life Sciences, Linnaeus University, 39231 Kalmar, Sweden

2 Functional Materials, Applied Physics Department, School of Engineering Sciences (SCI), KTH Royal Institute of Technology, Stockholm, Sweden could incorporate recovery of the contaminants like $\mathrm{Pb}$ for use in batteries, radiation shielding and other protective coatings (Mutafela et al. 2019; Yu et al. 2016).

The only documented method of $\mathrm{Pb}$ recovery from crystal glass waste is pyrometallurgy through reduction-melting (Jani and Hogland, 2017), an energy-intensive $\left(1100{ }^{\circ} \mathrm{C}\right)$ process that also emits $\mathrm{Pb}$-containing particulates $(\mathrm{Li}$ et al. 2019). Thus, an alternative process is needed to lower the energy footprint and eliminate such emissions. The mechanochemical process, a potential alternative, combines mechanical activation of the glass with hydrometallurgy in $\mathrm{Pb}$ extraction (Sasai et al. 2008). Although glass is structurally too stable for ordinary leaching methods to fully liberate elements from its matrix, mechanical activation can destabilise its structure for easy dissolution of $\mathrm{Pb}$ ions during leaching (Singh et al. 2016).

The current study, therefore, focuses on the potential for lower-energy extraction of $\mathrm{Pb}$ from crystal glass waste through mechanical activation and leaching with nitric acid $\left(\mathrm{HNO}_{3}\right)$. Recovery potential was investigated at different leaching temperatures, times and varying acid concentrations. Some activated glass samples were water-leached and lead sulphide $(\mathrm{PbS})$ formation from the leached $\mathrm{Pb}$ was assessed. 


\section{Materials and methods}

\section{Sampling and mechanical activation of samples}

The crystal glass sample investigated was obtained from Madesjö glass waste dump in Nybro, southeastern Sweden. The sample was crushed to smaller pieces, pulverised in a ball mill and sieved to $<125 \mu \mathrm{m}$ samples, herein referred to as milled glass. The milled sample was then oven-dried at $105{ }^{\circ} \mathrm{C}$ for $24 \mathrm{~h}$. Forty grams of the sample was mechanically activated in a $250 \mathrm{ml}$ agate jar of a planetary ball mill with 10 agate balls of $15 \mathrm{~mm}$ diameter. The activation was done for $180 \mathrm{~min}$ at $500 \mathrm{rpm}$, after which the activated glass sample was oven-dried at $105^{\circ} \mathrm{C}$ for $24 \mathrm{~h}$.

\section{Metal extraction process and lead sulphide formation}

Some samples were treated by acid leaching and others by water leaching and sulphidation using a thermostatically controlled shaking water bath (Grant OLS200) at constant solid to liquid ratio. For water leaching, $2 \mathrm{~g}$ each of milled and activated glass sample was agitated in $40 \mathrm{ml}$ deionized water at room temperature for $150 \mathrm{~min}$ to assess the change in metal availability caused by the mechanical activation process. To generate $\mathrm{PbS}$, another $2 \mathrm{~g}$ of activated glass sample was similarly agitated with $0.15 \mathrm{~g}$ of analytical grade elemental Sulphur, but at $70{ }^{\circ} \mathrm{C}, 95^{\circ} \mathrm{C}$ and $120^{\circ} \mathrm{C}$ (in an autoclave), respectively. After each run, the contents were separated by vacuum filtration.

Acid leaching was carried out at $25^{\circ} \mathrm{C}, 70{ }^{\circ} \mathrm{C}$ and $95^{\circ} \mathrm{C}$ in each acid concentration of $0.5 \mathrm{M}, 1 \mathrm{M}$ and $3 \mathrm{M} \mathrm{HNO}_{3}$, respectively. In each case, $2 \mathrm{~g}$ of activated sample was agitated with $500 \mathrm{~mL} \mathrm{HNO}_{3}$ in $1 \mathrm{~L}$ flasks for $12 \mathrm{~h}$. During the leaching process, $10 \mathrm{~mL}$ samples were collected from the flasks at five time points $(0.5 \mathrm{~h}, 1 \mathrm{~h}, 2 \mathrm{~h}, 6 \mathrm{~h}$ and $12 \mathrm{~h})$ and centrifuged immediately after leaching, before metal content analyses. $\mathrm{Pb}$ extraction efficiency was expressed in terms of metal recovery (\%) as follows (Wuana et al. 2010):

Metal recovery $(\%)=\frac{C_{1} V_{1}}{C_{\mathrm{s}} m_{\mathrm{s}}} \times 100$

where $C_{1}$ and $C_{\mathrm{s}}$ are the metal concentrations in supernatant $\left(\mathrm{mg} \mathrm{L}^{-1}\right)$ and glass $\left(\mathrm{mg} \mathrm{kg}^{-1}\right)$ respectively; $V_{1}$ is the volume of supernatant (L) and $m_{s}$ is the dry mass of the glass $(\mathrm{kg})$ samples.

\section{Sample characterisation and metal analyses}

The milled glass sample was analysed for elemental composition, whereas both milled and activated samples were analysed for morphology, specific surface area, particle size, pore size distribution and volume. In addition, filtration residues from the sulphidation process were analysed for phase identification ( $\mathrm{PbS}$ peaks) and surface charge, whereas the supernatant $\left(C_{1}\right.$ in Eq. 1$)$ from the acid leaching and sulphidation processes were analysed for metal contents (discussed further in Supplementary Material).

\section{Experimental design and statistical analyses}

The effects of leaching temperature, time and acid concentration on $\mathrm{Pb}$ extraction were studied based on factorial design of experiments (Montgomery. 2001) and according to the following polynomial equation:

$$
\begin{aligned}
R= & a 0+a 1 \times C+a 2 \times T+a 3 \times T i+a 4 \times C \times T \times T i \\
& +a 5 \times C^{2}+a 6 \times T^{2}+a 7 \times T i^{2}
\end{aligned}
$$

where $R$ is the extraction efficiency (\%), $a(0-6)$ are the model constants, $C$ is the acid concentration in moles (M), $T$ is the temperature in degrees Celsius $\left({ }^{\circ} \mathrm{C}\right)$ and $T i$ is the time in seconds. STATISTICA version 6 was used to determine the predicted recovery results and the polynomial equation constants based on the Least Square method.

\section{Results and discussion}

\section{Composition of elements in the glass sample}

Elemental composition of the milled glass sample was determined as shown in Table 1. According to Swedish limits

Table 1 Composition of elements in the crystal glass sample scanned by X-ray fluorescence. Based on Swedish limits for hazardous waste (Elert et al. 2019), some elements are in hazardous concentrations

\begin{tabular}{lll}
\hline Element & Concentration $\left(\mathrm{mg} \mathrm{kg}^{-1}\right)$ & $\begin{array}{l}\text { Swedish } \\
\text { Limits } \\
\left(\mathrm{mg} \mathrm{kg}^{-1}\right)\end{array}$ \\
\hline $\mathrm{As}$ & 16,226 & 1000 \\
$\mathrm{Cd}$ & 2624 & 1000 \\
$\mathrm{Co}$ & 50 & 1000 \\
$\mathrm{Cr}$ & 43 & 1000 \\
$\mathrm{Cu}$ & $<\mathrm{LOD}$ & 2500 \\
$\mathrm{Mn}$ & 85 & \\
$\mathrm{Mo}$ & $<\mathrm{LOD}$ & 10,000 \\
$\mathrm{Ni}$ & 1218 & 1000 \\
$\mathrm{~Pb}$ & 415,576 & 2500 \\
$\mathrm{Sb}$ & 10,224 & 10,000 \\
$\mathrm{Si}$ & 539,141 & \\
$\mathrm{Zn}$ & 476 & 2500 \\
\hline
\end{tabular}

$L O D$ limit of detection 
for hazardous waste (Elert et al. 2019), the elements As, $\mathrm{Cd}, \mathrm{Ni}, \mathrm{Pb}$ and $\mathrm{Sb}$ were in hazardous concentrations while $\mathrm{Cr}, \mathrm{Co}, \mathrm{Cu}, \mathrm{Mo}$ and $\mathrm{Zn}$ were lower than their respective hazardous waste limits. The limits of $\mathrm{Si}$ and $\mathrm{Mn}$ were not stated. The element of interest $(\mathrm{Pb})$ constituted $41.6 \%$ of the total elemental concentration in the sample. Concentration of each element corresponded with its use in crystal glass production (Mutafela et al. 2020b).

\section{Characteristics of the milled and activated glass samples}

Initial glass milling and sieving through a $125 \mu \mathrm{m}$ sieve produced varying particles sizes with sharp edges as shown in Fig. 1a. Mechanical activation reduced the particle sizes further, ranging between 200 and $500 \mathrm{~nm}$ with agglomeration (Fig. 1b). This conforms with particle sizes evaluated by dynamic light scattering method in Fig. 1c indicating primary particles between 200 and $300 \mathrm{~nm}$ and secondary agglomerates around $960 \pm 270 \mathrm{~nm}$. Mechanical activation altered glass physical properties to enhance the leaching process, as further discussed in the Supplementary Material.

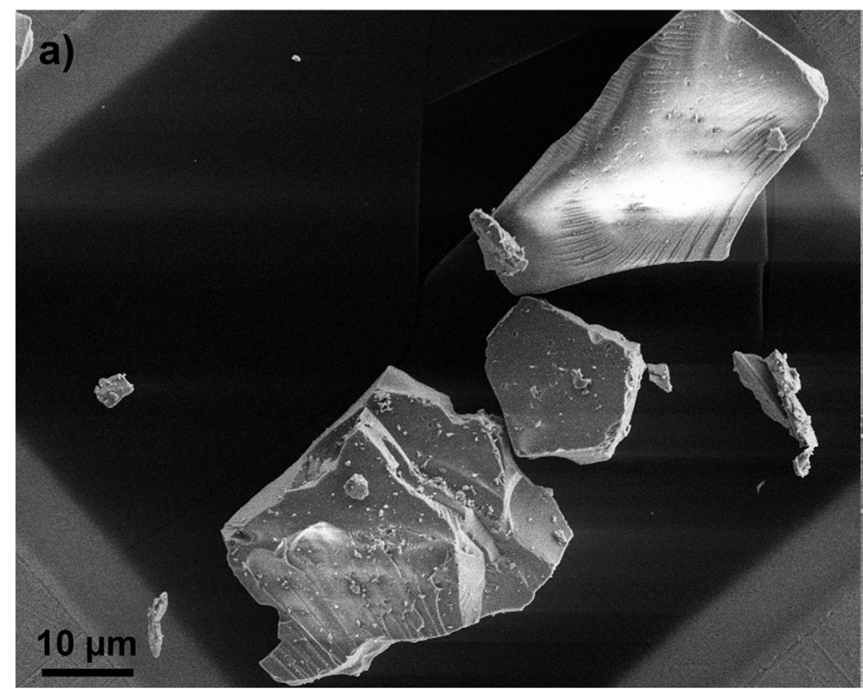

c)

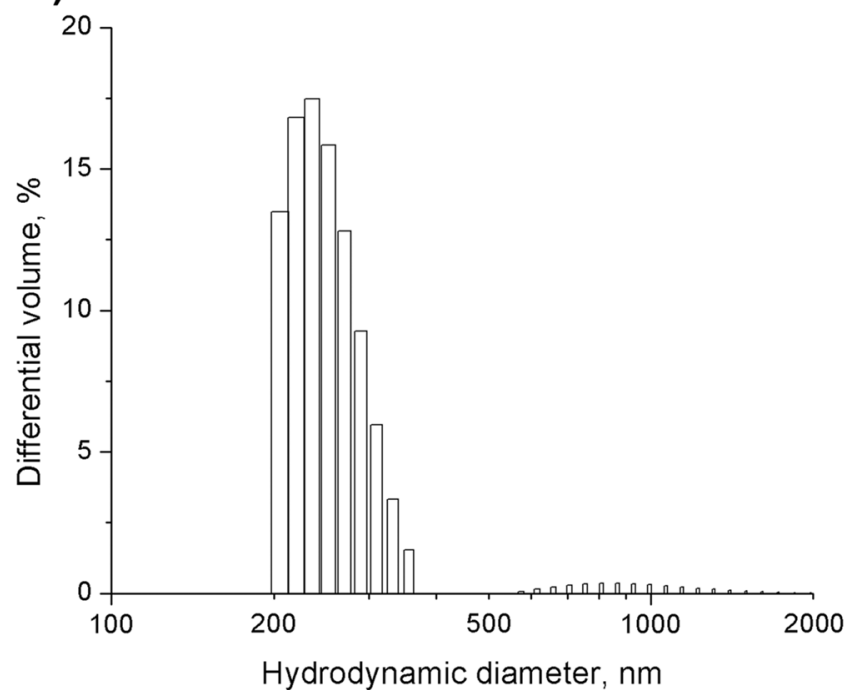

Fig. 1 Scanning electron microscopy images of a milled sample and b mechanically activated sample with inset showing details of one area with higher magnification; c volume-weighted hydrodynamic size distribution of aqueous dispersion of activated glass sample. The size between 200 and $300 \mathrm{~nm}$ correlates well with the size obtained

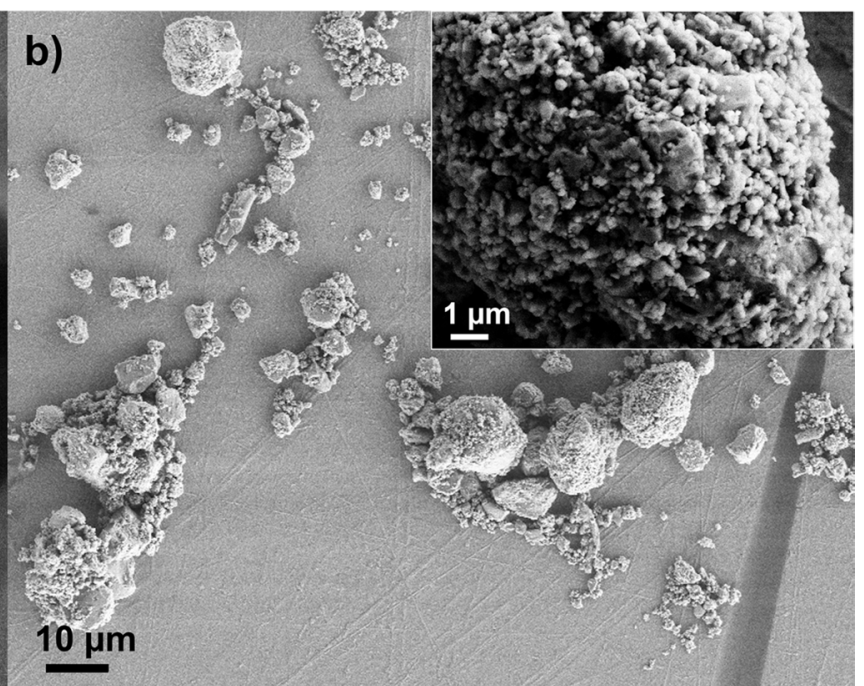

d)

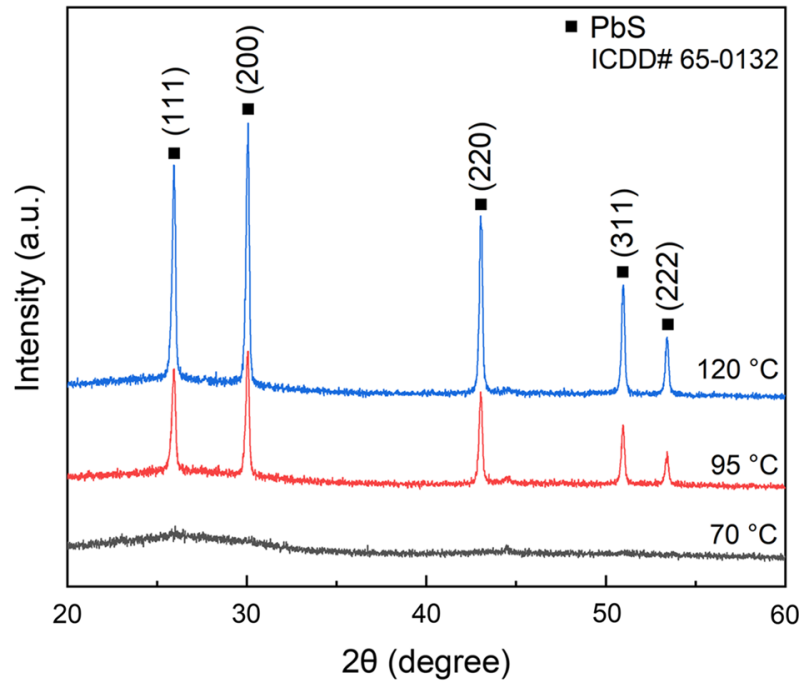

from scanning electron microscope imaging; d powder X-ray diffraction patterns of the $\mathrm{PbS}$ formed at $70{ }^{\circ} \mathrm{C}, 95{ }^{\circ} \mathrm{C}$ and $120{ }^{\circ} \mathrm{C}$. Amorphous phase was obtained at $70^{\circ} \mathrm{C}$, while highly pure crystalline $\mathrm{PbS}$ was obtained at $95^{\circ} \mathrm{C}$ and $120^{\circ} \mathrm{C}$ 


\section{Sulphidation process}

The potential for $\mathrm{PbS}$ generation from leached $\mathrm{Pb}$ was assessed at different temperatures to determine the most suitable temperature for crystallization. In Fig. 1d, the $\mathrm{PbS}$ obtained at $70{ }^{\circ} \mathrm{C}$ only had a broad peak between $25^{\circ}$ and $30^{\circ}$, suggesting its amorphous nature. For $95^{\circ} \mathrm{C}$ and $120^{\circ} \mathrm{C}$ treatments, sharp peaks were observed at $25.9^{\circ}, 30.0^{\circ}, 43.0^{\circ}$, $51.0^{\circ}$ and $53.4^{\circ}$, which can be indexed to crystal planes of (111), (200), (220), (311) and (222), respectively, according to the International Centre for Diffraction Data (ICDD) Card No.65-0132 (Chongad et al. 2016). Apart from PbS, no other crystalline phases were observed, implying higher purity of the $\mathrm{PbS}$ generated at $95{ }^{\circ} \mathrm{C}$ and $120^{\circ} \mathrm{C}$. Using the Scherrer equation, the average crystalline sizes of $\mathrm{PbS}$ nanoparticles were determined from the highest intensity diffraction peak ((200) plane) as $37.4 \mathrm{~nm}$ and $38.4 \mathrm{~nm}$ for $95{ }^{\circ} \mathrm{C}$ and $120{ }^{\circ} \mathrm{C}$, respectively. Higher temperature generated slightly bigger grain sizes due to faster crystal growth rate. Effects of temperature on $\mathrm{PbS}$ generation are discussed further in Supplementary Material.

\section{Metal extraction}

The effect of concentration on extraction is shown as a plot of kinetics of each acid concentration at $25{ }^{\circ} \mathrm{C}, 70{ }^{\circ} \mathrm{C}$ and $95^{\circ} \mathrm{C}$ in Fig. 2a-c, respectively. The effect of temperature on leaching kinetics is shown in Fig. 2d. In this study, the kinetics was described based on chemical reaction control and film diffusion control, according to the two-phase exponential association model (Eq. 3) provided by OriginLab (2020):

$y=y_{0}+A_{1}\left(1-e^{-x / t_{1}}\right)+A_{2}\left(1-e^{-x / t_{2}}\right)$

The model generated fitting curves (dashed lines) shown in Fig. 2a-c, and model parameters $\left(R^{2}\right.$ and rate constants; $t_{1}$ and $t_{2}$ for the fast and slow steps, respectively) as shown in Table S1 (Supplementary Material). In the modelling based on Eq. 3, a straight line and zero point intercept were obtained for the first $30 \mathrm{~min}$ of the extraction process, indicating that the kinetics is controlled by the chemical reaction step at the particle surface (Sancho et al. 2009). The chemical reaction controlling step is expected due to the smaller particle sizes and increased surface area, whereby enough $\mathrm{Pb}$ ions are exposed and made readily available by the mechanical activation process, hence the rapid leaching in the first $30 \mathrm{~min}$. As the process proceeds beyond $30 \mathrm{~min}$, the available $\mathrm{Pb}$ ions on the particle surface are almost completely leached, and thus, diffusion through the glass particle layer dominates. The amorphous nature of the particles enables $\mathrm{Pb}$ ions to diffuse out of the solid phase into the liquid phase during the film diffusion control step. However, $\mathrm{Pb}$ ions at this stage are more closely bound to the solid phase than in the previous stage, hence the extraction rate slows down.
Fig. 2 Effect of acid concentration $\mathbf{a}-\mathbf{c}$ and temperature $\mathbf{d}$ on $\mathrm{Pb}$ extraction. The differences in extraction due to acid concentration were not significant for all temperatures. The leaching kinetics increased with temperature and the highest $\mathrm{Pb}$ extraction $(78 \%)$ was achieved by $3 \mathrm{M} \mathrm{HNO}_{3}$ at $95{ }^{\circ} \mathrm{C}$ after $12 \mathrm{~h}$ of leaching
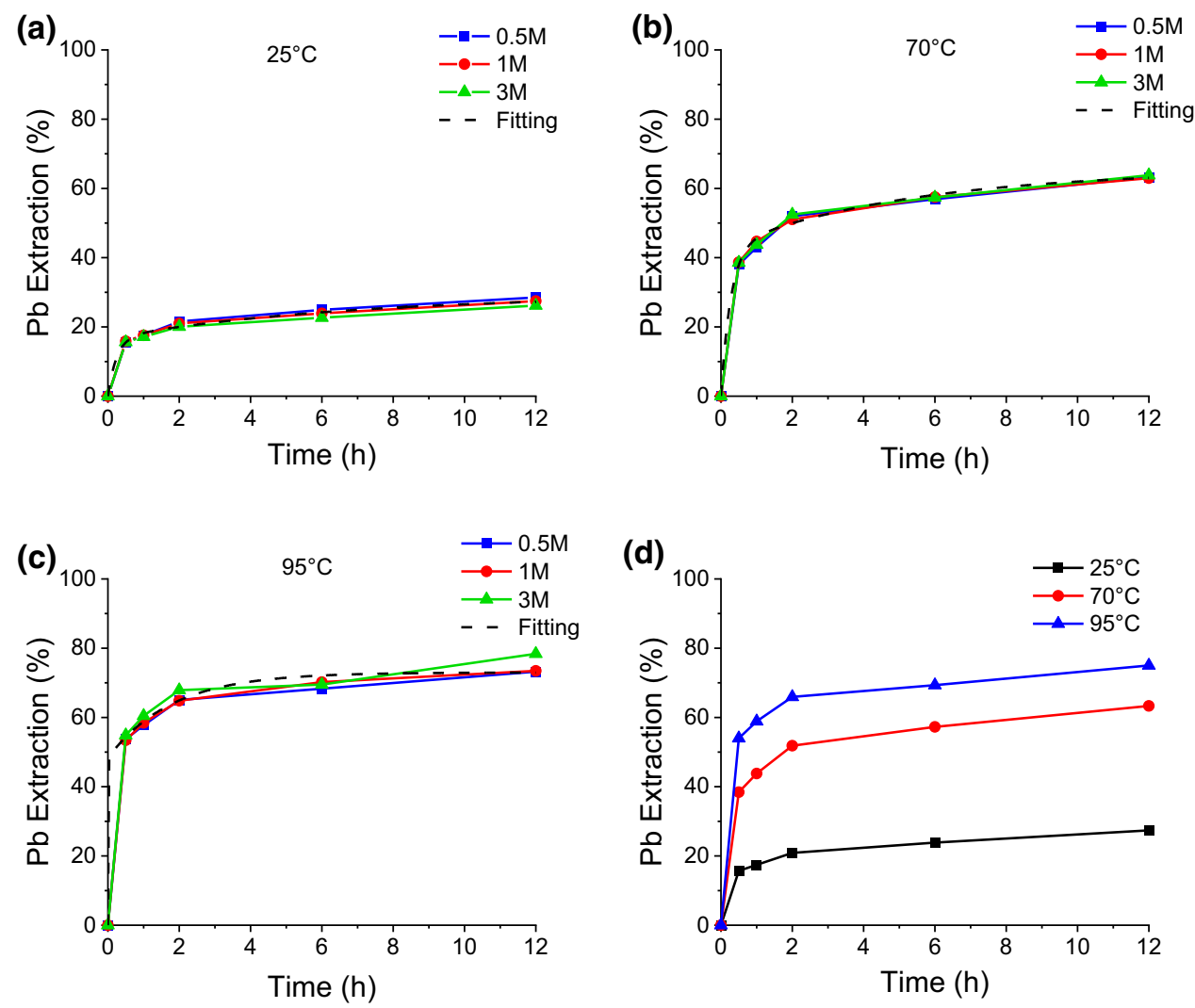

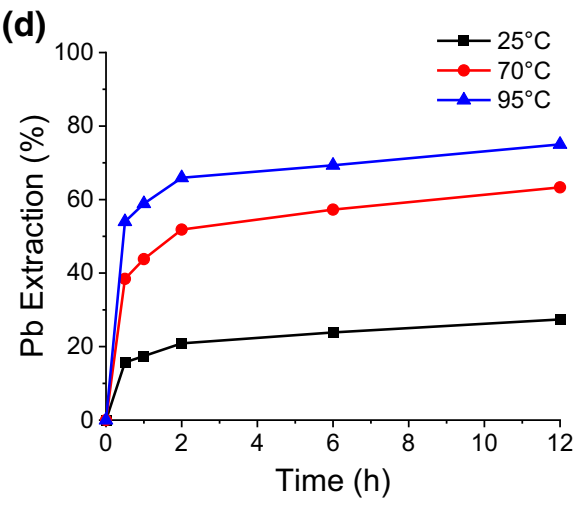


Fig. 3 Comparison between experimental (observed) and theoretical (predicted) values of the percentage of $\mathrm{Pb}$ extraction. The results of the correlation coefficient revealed positive relation between each two variables and confirmed the mutual interaction between the three studied parameters (temperature, time and acid concentration) on the extraction efficiency of $\mathrm{Pb}$

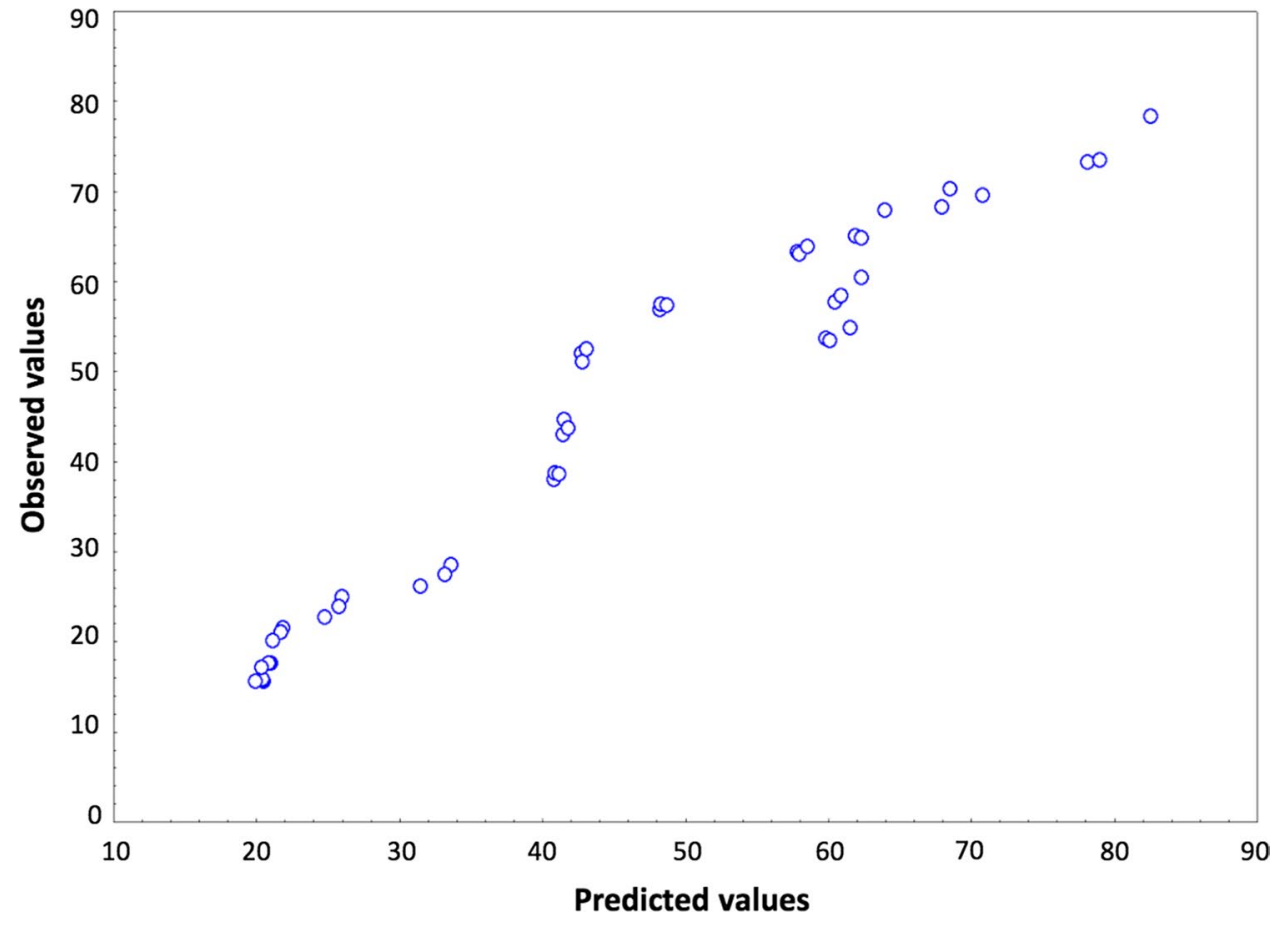

\section{The effect of concentration}

In the first $30 \mathrm{~min}$, the leaching showed a burst mode for all three concentrations of $\mathrm{HNO}_{3}$ at each temperature, after which it progressed at a lower rate. After $2 \mathrm{~h}$, the leaching efficiency increased very slowly and almost reached plateau at $12 \mathrm{~h}$. At $25^{\circ} \mathrm{C}$ (Fig. 2a), extraction slightly decreased with increase in acid concentration. At $70{ }^{\circ} \mathrm{C}$ (Fig. 2b), similar extraction trends were observed, whereas at $95^{\circ} \mathrm{C}$ and $3 \mathrm{M}$ $\mathrm{HNO}_{3}$ (Fig. 2c) slightly higher extraction was observed. However, the differences in extraction due to concentration were insignificant at all temperatures, implying potential for an economically higher efficiency using $0.5 \mathrm{M} \mathrm{HNO}_{3}$. The relation between metal extraction and solubility of extracted product is further discussed in the Supplementary Material.

\section{The effect of temperature}

Extraction results were averaged for each temperature as shown in Fig. 2d. Extraction in the first 30 min increased rapidly with increase in temperature, implying a positive effect. After $30 \mathrm{~min}$, extraction was $15 \%, 40 \%$ and $55 \%$ for $25{ }^{\circ} \mathrm{C}, 70{ }^{\circ} \mathrm{C}$ and $95{ }^{\circ} \mathrm{C}$, respectively. Although the leaching kinetics increase with temperature, the extraction percentage at 30 min compared to the final leached amounts remains the same for all three temperatures, accounting for $75 \%$. Therefore, repeated cycles with $30 \mathrm{~min}$ processing time could be designed to maximise metal extraction. Overall, the highest $\mathrm{Pb}$ extraction (78\%) was achieved by $3 \mathrm{M} \mathrm{HNO}_{3}$ at $95{ }^{\circ} \mathrm{C}$ after $12 \mathrm{~h}$ of leaching. The results further indicate that although metal ions are firmly fixed in the crystal glass structure rendering extraction under normal conditions highly unlikely (Singh et al. 2016), mechanical activation of the glass successfully destroyed the glass inner structure, thus facilitating easy dissolution of higher amounts of $\mathrm{Pb}$ (Yu et al. 2016).

The results are comparable to a similar study on $\mathrm{Pb}$ extraction, but in alkaline solution, where maximum extraction was $67 \%$ after $2 \mathrm{~h}$ of extraction in $5 \mathrm{M} \mathrm{NaOH}$ solution at $80{ }^{\circ} \mathrm{C}$ (Zhang et al. 2016). Although the concentration $(0.5 \mathrm{M})$ in the current study is lower than $5 \mathrm{M}$ in the previous study, the extraction range and time required are similar. Contrarily, higher $\mathrm{Pb}$ extraction efficiencies through reduction-melting have been reported (Jani \& Hogland. 2017; Zhang et al. 2016), although these methods are very energyintensive compared to the current study.

\section{Statistical analysis}

According to the statistical results shown in Fig. 3 and Table S2, the proposed polynomial equation fits the experimental results quite well with a high correlation coefficient $\left(R^{2}=0.9901\right)$. In Fig. 3, the results of the correlation coefficient revealed positive relation between each two variables and confirmed the mutual interaction between the three studied parameters (temperature, time and acid concentration) on the extraction efficiency of $\mathrm{Pb}$. When $R^{2}$ approaches \pm 1 , the relationship between the two operating conditions is linear with high interaction between the two variables. In a comparison of all the variables with recovery, a One-way 
ANOVA analysis of the difference among the variables of the proposed model equation showed that the results were significant $(P<0.05)$.

\section{Conclusion}

Extraction of $\mathrm{Pb}$ from contaminated crystal glass waste was investigated to achieve decontamination and resource recovery. Glass samples were mechanically activated and leached with nitric acid $\left(\mathrm{HNO}_{3}\right)$, focusing on the effects of leaching temperature, time and acid concentration on extraction efficiency. Mechanical activation of the glass enhanced $\mathrm{Pb}$ extraction significantly during acid leaching, making it a vital complimentary step to traditional leaching techniques. The first $30 \mathrm{~min}$ of reaction were important for the extraction since about $75 \%$ of the final extracted amounts was already extracted within this time, with lower leaching rate observed beyond the $30 \mathrm{~min}$. This indicates potential for shorter reaction time with optimised experimental parameters favouring $30 \mathrm{~min}$. Acid concentration also showed insignificant effect on extraction efficiency, which indicates economic feasibility through the use of lower acid concentration for similar results. Temperature, on the other hand, showed the highest effect on extraction efficiency. Overall, the highest extraction achieved was $78 \%$ in $3 \mathrm{M} \mathrm{HNO}_{3}$ and at $95{ }^{\circ} \mathrm{C}$. This study introduces mechanochemical extraction of $\mathrm{Pb}$ from crystal glass as a lower-energy alternative to pyrometallurgy, which could contribute to glass decontamination and resource recovery.

Acknowledgements We thank staff at Högbytorp Laboratory (Stockholm) for their input.

Funding Open access funding provided by Linnaeus University. The authors received no external financial support for this work.

\section{Compliance with ethical standards}

Conflict of interest The authors declared no conflicts of interest.

Open Access This article is licensed under a Creative Commons Attribution 4.0 International License, which permits use, sharing, adaptation, distribution and reproduction in any medium or format, as long as you give appropriate credit to the original author(s) and the source, provide a link to the Creative Commons licence, and indicate if changes were made. The images or other third party material in this article are included in the article's Creative Commons licence, unless indicated otherwise in a credit line to the material. If material is not included in the article's Creative Commons licence and your intended use is not permitted by statutory regulation or exceeds the permitted use, you will need to obtain permission directly from the copyright holder. To view a copy of this licence, visit http://creativecommons.org/licenses/by/4.0/.

\section{References}

Brião GdV, de Andrade JR, da Silva MGC, Vieira MGA (2020) Removal of toxic metals from water using chitosan-based magnetic adsorbents. A review. Environ Chem Lett 18(4):1145-1168. https://doi.org/10.1007/s10311-020-01003-y

Chongad LS, Sharma A, Banerjee M, Jain A (2016) Synthesis of Lead sulfide nanoparticles by chemical precipitation method. J Phys Conf Ser 755:012032. https://doi.org/10.1088/17426596/755/1/012032

Elert M, Jones C, Broms S (2019) Uppdaterade bedömningsgrunder för förorenade massor (In Swedish). Malmö, Avfall Sverige

Jani Y, Hogland W (2017) Reduction-melting extraction of trace elements from hazardous waste glass from an old glasswork's dump in the southeastern part of Sweden. Environ Sci Pollut Res 24(34):26341-26349. https://doi.org/10.1007/s11356-017-0243-4

Keng PS, Lee SL, Ha ST, Hung YT, Ong ST (2014) Removal of hazardous heavy metals from aqueous environment by low-cost adsorption materials. Environ Chem Lett 12(1):15-25. https:// doi.org/10.1007/s 10311-013-0427-1

Li Y, Yang S, Lin W, Taskinen P, He J, Wang Y, Jokilaakso A (2019) Cleaner extraction of lead from complex lead-containing wastes by reductive sulfur-fixing smelting with low SO2 emission. Minerals 9(2):119. https://doi.org/10.3390/min9020119

Malik LA, Bashir A, Qureashi A, Pandith AH (2019) Detection and removal of heavy metal ions: a review. Environ Chem Lett 17(4):1495-1521. https://doi.org/10.1007/s10311-019-00891-z

Montgomery DC (2001) Design and analysis of experiments, 5th edn. Wiley, New York

Mutafela RN, Mantero J, Jani Y, Thomas R, Holm E, Hogland W (2020a) Radiometrical and physico-chemical characterisation of contaminated glass waste from a glass dump in Sweden. Chemosphere 241:124964. https://doi.org/10.1016/j.chemospher e.2019.124964

Mutafela RN, Lopez EG, Dahlin T, Kaczala F, Marques M, Jani Y, Hogland W (2020b) Geophysical investigation of glass 'hotspots' in glass dumps as potential secondary raw material sources. Waste Manag 106:213-225. https://doi.org/10.1016/j.wasma n.2020.03.027

Mutafela RN, Marques M, Jani Y, Kriipsalu M, Hogland W (2019) Physico-chemical characteristics of fine fraction materials from an old crystal glass dumpsite in Sweden. Chem Ecol 35(9):877-890. https://doi.org/10.1080/02757540.2019.1648442

Pasalari H, Farzadkia M, Gholami M, Emamjomeh MM (2019) Management of landfill leachate in Iran: valorization, characteristics, and environmental approaches. Environ Chem Lett 17(1):335348. https://doi.org/10.1007/s10311-018-0804-x

Rossini P, Matteucci G, Guerzoni S (2010) Atmospheric fall-out of metals around the murano glass-making district (Venice, Italy). Environ Sci Pollut Res 17(1):40-48. https://doi.org/10.1007/s1135 6-009-0122-8

Sancho JP, Ayala J, García MP, Fernández B (2009) Leaching behaviour of a bayer electrofilter fines in sulphuric acid. Hydrometallurgy 96(1):35-41. https://doi.org/10.1016/j.hydro met.2008.07.007

Sasai R, Kubo H, Kamiya M, Itoh H (2008) Development of an ecofriendly material recycling process for spent lead glass using a mechanochemical process and Na2EDTA reagent. Environ Sci Technol 42(11):4159-4164. https://doi.org/10.1021/es0719576

Singh N, Li J, Zeng X (2016) An innovative method for the extraction of metal from waste cathode ray tubes through a mechanochemical process using 2-[Bis(carboxymethyl)amino]acetic acid chelating reagent. ACS Sustain Chem Eng 4(9):4704-4709. https://doi. org/10.1021/acssuschemeng.6b00875 
Wuana RA, Okieimen FE, Imborvungu JA (2010) Removal of heavy metals from a contaminated soil using organic chelating acids. Int J Environ Sci Technol 7(3):485-496. https://doi.org/10.1007/ BF03326158

Yu G, Tian XM, Wu YF, Zhe T, Lei L (2016) Recent development of recycling lead from scrap CRTs: a technological review. Waste Manag 57:176-186. https://doi.org/10.1016/j.wasma n.2015.09.004

Zhang C, Zhuang L, Yuan W, Wang J, Bai J (2016) Extraction of lead from spent leaded glass in alkaline solution by mechanochemical reduction. Hydrometallurgy 165:312-317. https ://doi.org/10.1016/j.hydromet.2016.01.017

Publisher's Note Springer Nature remains neutral with regard to jurisdictional claims in published maps and institutional affiliations. 